\title{
New Evidence for the Present-Value Model of Stock Prices: Why the REH Version Failed Empirically
}

\author{
Roman Frydman, ${ }^{1}$ Michael D. Goldberg, ${ }^{2}$ Nicholas Mangee $^{3}$
}

\author{
Working Paper No. 2
}

\author{
February 2nd, 2015
}

\begin{abstract}
Shiller (1981) and others have shown that the quantitative predictions of the REH present-value model are inconsistent with time-series data on stock prices and dividends. In this paper, we assess the empirical relevance of the model without explicitly representing how a rational market participant forecasts dividends and interest rates. We find that stock prices are driven largely by news about fundamental factors. Moreover, this news moves prices through changes in the market's forecasts of dividends and/or interest rates in ways that are remarkably consistent with the present-value model. We also find that the structure of the process underpinning stock prices

\footnotetext{
${ }^{1}$ Department of Economics, New York University and INET Program on Imperfect Knowledge Economics (IKE), http://econ.nyu .edu/user/frydmanr and http://ineteconomics org/researchprogram/imperfect-knowledge-economics, respectively.

${ }^{2}$ Peter T. Paul College of Business and Economics, University of New Hampshire, http://pubpages.unh.edu/ michaelg/, and INET Program on IKE.

${ }^{3}$ Department of Economics, Armstrong State University and INET Program on IKE.
} 
undergoes quantitative change, and that both fundamental and psychological factors play an important role in this process. Taken together, Shiller's findings and ours point to a novel explanation of the present-value model's empirical difficulties. They also imply that macroeconomists and finance theorists should rethink how to represent rational forecasting in real-world markets.

JEL Codes: E44, G12, G14

The authors are grateful to the Institute for New Economic Thinking (INET) for supporting this research. The authors thank Matt Winkler and Bloomberg News for providing access to the company's entire historical record of market wrap reports. 


\section{Introduction}

The present-value model is simple and intuitive. It relates movements in stock prices to changes in the forecast by the market (an aggregate of its participants) of the discounted value of companies' future dividends. The model implies that stock prices are driven by news about fundamental factors, such as companies' earnings and overall economic activity. It predicts that when this news raises (lowers) the market's forecast of dividends or lowers (raises) its forecast of interest rates, the market bids stock prices up (down).

Researchers typically represent these forecasts with the rational expectations hypothesis $(\mathrm{REH})$. The resulting model generates quantitative predictions concerning the co-movement between stock prices and fundamental factors. In a ground-breaking paper, Shiller (1981) pointed out that these predictions are grossly inconsistent with time-series data on how stock prices and dividends actually unfold over time.

In this paper, we assess the empirical relevance of the present-value model, without explicitly representing how a rational market participant forecasts dividends and interest rates. We find that stock prices are driven largely by news about fundamental factors. Moreover, this news moves prices through changes in the market's forecasts of dividends and/or interest rates in ways that are remarkably consistent with the present-value model's main qualitative predictions. We also find that the structure of the process underpinning dividends and interest rates, and thereby stock prices, undergoes quantitative change.

These findings accord with econometric studies that also find structural change in the price process. These studies do not typically address the question of whether the quantitative change that they estimate on the basis of ex post data could have been anticipated ex ante, or, equivalently, whether their estimated models would provide an adequate account of future change.

That question - whether structural change can be fully anticipated is particularly relevant in the context of the present-value model, which involves forecasts of dividends and interest rates into the distant future. REH models' core premise is that quantitative change in the structure 
of the process underpinning outcomes can be fully anticipated. ${ }^{1}$

We present evidence that this structural change in equity markets could not have been fully anticipated in advance, even in probabilistic terms. As such, the estimated relationships found in ex post data should not be expected to approximate adequately the relationships that might hold in the future.

Taken together, Shiller's findings and ours point to a novel explanation of the present-value model's empirical difficulties: profit-seeking compels rational participants in real-world markets to recognize unanticipated structural change. REH models rule out such change, and thus represent decision-making and forecasting by individuals who forego profit opportunities. Consequently, because market participants are rational, the REH present-value model cannot account for time-series regularities in the co-movements between dividends and stock prices. ${ }^{2}$

In assessing the empirical relevance of the present-value model, we make use of a novel data set. Mangee (2011) manually reads Bloomberg News market wraps and codes them numerically for only those factors that are explicitly identified as having moved major market indices, such as the Standard and Poor's (S\&P) 500, on a given day. Bloomberg journalists monitor and report on US stock-market developments throughout the day. The market wraps summarize these intraday reports, which are partly based on interviews with fund managers and other market participants.

Mangee's data set begins on January 4, 1993 (the inception of Bloomberg's market wraps), and runs through December 31, 2009. Manual reading enables him to use human reasoning to understand the context and extract only relevant information. But, in order to ensure that the wraps

\footnotetext{
${ }^{1}$ This premise obviously applies to a vast majority of REH models, which constrain their structure to be time-invariant. The present-value model estimated by Campbell and Shiller $(1988 \mathrm{a}, \mathrm{b})$ is just one example. But the same premise underpins multipleequilibrium models (Timmermann, 1994 and Obstfeld, 1994) and those that represent change with a probabilistic switching rule (Hamilton, 1988). The latter class fully specifies in advance not only all possible quantitative changes, but their timing as well.

${ }^{2}$ See section 6 for a sketch of this argument. For a rigorous demonstartion in the context of the present-value model, see Frydman and Goldberg (2015).
} 
are scored consistently over the 17-year period, Mangee adheres to a strict set of rules.

Mangee's rule-based reading reveals that market participants' forecasting is underpinned by news on a wide range of fundamental factors, ranging from company reports and earnings announcements to speeches by Federal Reserve officials and political developments, both in the US and abroad. But his reading shows that psychological considerations, such as confidence, optimism, and fear, as well as chartist considerations, such as momentum trading, also play a role in market participants' trading decisions. Beyond tracking the factors that are explicitly mentioned as having driven the market's forecasts of dividends and the real interest rate, Mangee records whether participants interpreted the news about these factors to have had a positive or negative impact on a given day's stock prices.

Analysis of this data set supports our interpretation of the empirical failure of the REH present-value model. This failure stems from neither the model itself, nor from a disconnection between stock prices and fundamental factors. Rather, the model's empirical failure reflects REH's inherent inability to represent how rational, profit-seeking individuals understand and forecast outcomes in terms of fundamentals. Bloomberg's wraps provide considerable evidence that participants in real-world markets not only rely on fundamental factors, but that they revise their strategies for relating these factors to future outcomes at times and in ways that they could not have fully anticipated, even with a probabilistic rule.

But once one attempts to account for time-series data that ignore such change, as Shiller and others do, stock prices appear "too volatile to be accounted for by news about future dividends [or other fundamental factors]" (Campbell and Shiller, 1988b, p. 662). As a result, behavioral researchers developed "bubble" models, which, in sharp contrast to the REH present-value model, relate stock prices to psychological or technical factors that are largely unrelated to fundamental factors.

Bloomberg's wraps document that psychological factors do play an important role in driving daily price movements. However, contrary 
to the bubble view, Mangee's data reveal that whenever psychological factors mattered, participants almost always related them to the day's news about fundamental factors. This is what we would expect when one cannot rely on calculation and statistical analysis alone in deciding how to forecast future outcomes on the basis of fundamentals.

As Shiller (2014, p. 1494) put it in his Nobel lecture, "there is no objective way to forecast dividends out for decades." This is the case precisely because quantitative structural change cannot be fully anticipated. Rational market participants must therefore rely on psychological factors to help them interpret how fundamentals relate to future outcomes.

The remainder of the paper is structured as follows. In Section 2, we sketch the present-value model and relate its predictions of stock-price movements to changes in the market's forecast of dividends and interest rates, without taking a position on how these forecasts are related to fundamental factors. In Section 3, we compare our approach to converting narrative information into numerical data with the usual practice of relying on automated programs. We explain why the inherent difficulties of using such programs to assess the relevance of the present-value model led us to rely on rule-based manual reading. Section 4 reports our empirical findings concerning the main predictions of the present-value model, Section 5 presents our evidence on structural change, and shows that this change could not have been fully anticipated. In Section 6, we present evidence of how psychological factors and other non-fundamental factors matter for price movements, and consider the bubble view in light of this evidence. We also offer our novel explanation of the REH present-value model's empirical difficulties.

\section{The Present-Value Model}

The derivation of the present-value model is well known. It makes use of Muth's (1961) seminal insight that an economist can represent how the market understands and forecasts stock prices by imposing coherence between the market's and his own understanding of the process driving price movements.

We formalize an economist's understanding with Campbell and Shiller's 
(1988a,b) log-linear specification. We assume that the market's expected excess return on stocks over short-term debt (typically commercial paper or Treasury bills) is constant in equilibrium:

$$
p_{t}=\mathcal{F}_{t}^{\mathrm{M}}\left(\rho p_{t+1}+(1-\rho) d_{t+1}-r_{t+1} \mid v_{t}\right) \quad \text { for all } t
$$

where $p_{t}$ and $d_{t+1}$ denote the log price of a stock or a basket of stocks in period $t$ and the next-period's log dividend, respectively, $r_{t+1}$ is the interest rate on the alternative asset between $t$ and $t+1$, and $0<\rho<1$ is a parameter of linearization that serves as a discount factor. ${ }^{3}$

$\mathcal{F}_{t}^{\mathrm{M}}\left(\cdot \mid v_{t}\right)$ represents the market's time- $t$ point forecast conditional on the information about the factors that it considers relevant, denoted by $v_{t}$. The market's information set is usually thought to consist of fundamental factors. For example, we would expect that market participants would rely on recent trends in companies' earnings in forecasting dividends or monetary policy announcements in forecasting interest rates. The $t$ subscript on the $\mathcal{F}_{t}^{\mathrm{M}}(\cdot)$ operator recognizes that the strategy underpinning the markets' point forecast may change over time. ${ }^{4}$

Iterating (1) forward and imposing internal coherence between an economist's and the market's understanding of stock prices at each $t$ leads to the present-value model: ${ }^{5}$

$$
p_{t}=\sum_{k=0}^{\infty} \rho^{k} \mathcal{F}_{t}^{\mathrm{M}}\left[(1-\rho) d_{t+1+k}-r_{t+1+k} \mid v_{t}\right]
$$

\footnotetext{
${ }^{3}$ For ease of exposition, we ignore a constant term arising from linearization. We express the equilibrium condition in (1) in nominal terms which reflects how Bloomberg News reports news about prices, dividends, and interest rates.

${ }^{4}$ In REH models that represent outcomes with a probability distribution ex ante, $\mathcal{F}^{\mathrm{M}}\left(\cdot \mid v_{t}\right)$ is the mathematical expectation of the distribution. Models that are open to unanticipated structural change do not imply such probabilistic representations. In these models, $\mathcal{F}_{t}^{\mathrm{M}}\left(\cdot \mid v_{t}\right)$ denotes the market's point forecast. For the properties of this operator and a comparison with the expectations opertaor, see Frydman and Goldberg (2015).

${ }^{5}$ In a model that is open to unanticipated structural change, the law of iterated expectations does not hold. Forward iteration and imposition of internal coherence, therefore, results in additional terms involving the market's iterated forecasts of dividends. Frydman and Goldberg (2015) show that the qualitative implications of the model are unaltered by exlcuding these additional terms.
} 
The model implies that fundamental factors' influence on stock prices

operates through two channels: the market's forecast of dividends and its forecast of interest rates. It predicts that, ceteris paribus, as the market raises (lowers) its forecast of the discounted value of dividends, or lowers (raises) its forecast of the discounted value of interest rates, it bids up (down) stock prices. Changes in these forecasts arise from two sources: news about the factors that the market considers relevant and revisions in how the market interprets this news in forecasting dividends and interest rates.

\section{A Direct Approach to Assessing the Present-Value Model's Empirical Relevance}

Researchers typically test the present-value model's main predictions indirectly. They use REH to relate the market's forecast of dividends and interest rates to a particular set of fundamental factors. The model then implies predictions concerning co-movements between stock prices and these factors, which are tested with econometric analysis of timeseries data.

Here, we assess the present-value model's empirical relevance without explicitly formalizing participants' forecasting. Doing so requires direct evidence concerning how participants in real-world markets relate stock-price movements to fundamental and other factors. Mangee (2011) extracts such evidence from narrative reports that Bloomberg News prepares at the end of every trading day.

\subsection{Automated Programs vs. Rule-Based Human Reading}

The use of narrative accounts in formal economic analysis poses a major challenge, because they often contain much information that is irrelevant for addressing researchers' questions. For this reason, researchers usually use an automated textual-analysis program to select relevant words or parts of a narrative account. A widely cited example of this methodology is Tetlock (2007), who examines the role of market sentiment in driving 
stock prices. His sentiment index is based on counting the number of "negative" and "positive" words in the Wall Street Journal's "Abreast of the Market" column. Words are selected and classified according to the "predetermined...categories from the Harvard Psychosocial Dictionary" (Tetlock, p.1140, emphasis in the original).

The fundamental problem with using predetermined categories is that language involves much nuance: words have multiple meanings, and discerning whether a word connotes positive or negative sentiment depends on the specific context in which it is used. Loughran and McDonald (2011) examine 10-K reports and find that three-fourths of the words counted as "negative" on the basis of Harvard's general categories typically do not have a negative connotation in a financial context. Boudoukh et al. (2012) also recognize this problem. They analyze phrase-level patterns in news stories with an automated system that attempts to distinguish between relevant and irrelevant news events.

Selecting relevant information from narrative accounts in order to assess the present-value model poses an even greater challenge than constructing sentiment measures. We need to score each Bloomberg News market wrap for only those factors that are explicitly identified as having moved stock prices on a given day. Using a content-analysis program to count the number of mentions is not an option. Even if we had a complete list of factors, such counts would grossly overestimate their importance, because Bloomberg's wraps often contain much text that is not directly connected to a day's stock-price movement. To score the market wraps, we need to understand the context in which factors were mentioned.

Moreover, we need to extract information about how participants interpret the impact of news on stock prices, which makes reliance on an automated program even more problematic. Specifically, we are interested in whether the influence of news on stock-price movements occurs through the present-value model's two channels: how participants understand and forecast either dividends or interest rates. 


\subsection{Mangee's Approach}

Mangee (2011) converts textual information into numerical data without the aid of a content-analysis program. Instead, he manually reads Bloomberg News's market wraps. This enables him to identify only those factors that are explicitly reported as a driver of stock prices on a given day. A strict set of rules ensures that the wraps are scored consistently over the 17 -year period. ${ }^{6}$

This rule-based manual approach is not constrained to search for words or phrases from a pre-specified list: any factor - whether fundamental, psychological, or technical - that is reported in a market wrap as a main driver of prices is recorded. Mangee also records whether a fundamental factor was mentioned as affecting prices positively or negatively. For example, if a rise (fall) in oil prices was mentioned as underpinning a rise (fall) in stock prices, he would record in his data set a $+1(-1)$ for oil prices on the date of the report. Herein lies one of the principal advantages of Mangee's approach over those that rely on automated textual analysis: Rule-based manual reading is able to track changes in the factors that participants consider relevant, as well as to changes in how they interpret the impact of these factors on price movements.

Understanding the context in which a factor is considered relevant enables Mangee to address a central problem inherent in all news-impact studies: what often matters for markets is not the actual change in a fundamental factor, but its change relative to what the market expected. Bloomberg journalists report the influence of such expectations when they are relevant for explaining market movements. ${ }^{7}$

In the Data Appendix, we consider excerpts from several Bloomberg market wraps to help clarify how Mangee constructs his data and how these wraps provide information about the process underpinning stock

\footnotetext{
${ }^{6}$ See the Data Appendix for a list of these rules.

${ }^{7}$ Bloomberg journalists rely largely on polling conducted by their firm's parent company, Bloomberg L.P., of the expectations of economists working at more than a hundred financial institutions and forecasting companies. These surveys often involve dozens of participants and are regularly conducted before the announcement of a broad range of key macroeconomic indicators. Bloomberg journalists sometimes also rely on Thompson-Reuters and other companies that regularly conduct surveys of professional participants' expectations.
} 
prices. The excerpts also show how the influence of expectations are incorporated into Bloomberg's reporting of the impact of fundamental factors.

To be sure, there is reason for skepticism regarding the scientific value of the information contained in Bloomberg's market wraps. After all, these wraps could merely reflect end-of-day rationalizations based on analysts' and journalists' a priori conceptions, which may have little connection to the developments and factors that actually drove market participants' forecasts and stock prices.

However, the process underpinning Bloomberg's reporting supports a high degree of confidence that Mangee's data do indeed contain information that is useful for understanding stock markets. Most important, Bloomberg journalists monitor developments in the US stock market throughout each trading day. They prepare multiple intraday reports as news and price developments occur. As earnings announcements are made or policy developments in Washington, DC, become known, they and everyone else can see the market react. Moreover, these reports regularly draw on interviews with hedge- and equity-fund managers and other professional participants. Bloomberg News wraps summarize the intraday reports in terms of the main factors that its journalists observed - and professional participants reported - had underpinned the day's price movements. ${ }^{8}$

Bloomberg's market wraps thus provide a uniquely rich source of information about market participants' decision-making and the key factors that they consider relevant in driving stock-price movements. ${ }^{9}$ Indeed, the demand for Bloomberg reports suggests that market par-

\footnotetext{
${ }^{8}$ The market wraps provide a rather extensive summary of a day's developments and are thus generally much longer in length than reports from other news sources. The wraps in our sample averaged 1,122 words, whereas a sample of recent Associated Press reports averaged 120 words.

${ }^{9}$ As far as we know, Mangee (2011) is the first study to construct a numerical data set based on Bloomberg News market wraps. Other textual sources that have been used in the literature include Dow Jones newswire feeds (Tetlock et al., 2008; Li, 2010; Cornell, 2012; and Boudoukh, 2013), Wall Street Journal columns (Tetlock, 2007, and Sullivan, 2013), Yahoo! Finance message boards (Antweiler and Frank, 2005 and Das and Chen, 2007), and corporate earnings releases (Davis et al., 2006, 2012; Engelberg, 2008 and Demers and Vega, 2010).
} 
ticipants themselves consider them relevant, if not indispensable, for understanding such movements. ${ }^{10}$

\subsubsection{The Factors Behind Price Movements}

Mangee records the factors that Bloomberg journalists report underpinned stock-price movements on each trading day from January 4, 1993, to December 31, 2009. He finds that 115 factors were mentioned as driving market movements on at least one day in the sample. We categorize these factors into three major groupings: fundamental, psychological, and technical factors, respectively.

Table A1 in the Data Appendix groups 85 fundamental factors into 16 broad categories. For example, the "macroeconomic activity" category includes 17 factors that are typically interpreted as measures of overall economic activity. Our empirical analysis in the next section focuses largely on these broader categories. Table A2 lists the psychological factors reported by Bloomberg News. Table A3 groups technical factors into two categories: those that involve some type of momentum or bandwagon behavior and those that are unrelated to such behavior.

\section{The Present-Value Model in Bloomberg News}

The present-value model implies that the major drivers of stock prices are news about fundamental factors and revisions in how the market interprets this news in forecasting dividends and interest rates. We first consider evidence on the role of fundamental factors in how market participants interpret and forecast movements in stock prices.

\subsection{The Central Role of Fundamentals}

One gauge of the relevance of a factor in moving stock prices is the proportion of trading days in the sample on which this factor was reported as having done so. Column 2 in Table 1 reports these frequencies for the three major groups and broad categories.

\footnotetext{
${ }^{10}$ Bloomberg L.P. is one of the largest financial news firms as measured by market share of financial professionals. Its subsidiary, Bloomberg News, is a major newswire service for more than 315,000 clients in 174 countries, including 450 newspaper and magazine outlets.
} 
Table 1: Factors that Moved the Market

\begin{tabular}{lcc}
\hline \hline Factor Categories $^{a}$ & \% Trading Days $^{b}$ & \% Positive Impact $^{c}$ \\
\hline Fundamentals & 99.4 & - \\
Dividends & 42.7 & 99.5 \\
Macroeconomic activity & 35.4 & 69.2 \\
Company variables & 23.1 & - \\
Sales & 23.2 & 91.3 \\
Oil & 20.2 & 45.4 \\
Interest rates & 17.3 & 1.9 \\
Rest of world & 14.2 & - \\
Benchmark valuation & 12.4 & 5.7 \\
Government & 11.7 & - \\
Central Bank & 9.6 & - \\
Housing & 8.2 & - \\
Inflation & 7.5 & 1.8 \\
Currency markets & 6.1 & 66.2 \\
Financial institutions & 6.3 & - \\
Geopolitical issues & 2.2 & - \\
Trade & 1.4 & - \\
\hline Psychological & 55.4 & - \\
Psychology w/ fundamentals & 54.6 & - \\
Pure psychology & 1.1 & - \\
\hline Technical & 6.3 & - \\
Momentum & 1.9 & - \\
Non-momentum & 4.9 & \\
\hline \hline
\end{tabular}

Notes: $a$ : Each category includes factors that Bloomberg News reported in at least one market wrap moved daily stock prices. For category definitions, see Tables A1-A3. $b:$ Each figure is the proportion of all trading days in the sample on which Bloomberg News reported that the factor moved stock prices. $c$ : The proportion of all mentions from Bloomberg market wraps for which the qualitative impact of a factor was reported as positive.

A frequency of $99.4 \%$ for the group of fundamental factors indicates that at least one of these factors was considered relevant on virtually every trading day in the sample. Table 1 reports that psychological factors were also mentioned quite frequently, but considerably less so; they mattered on roughly half of the trading days in the sample. The table also reveals that technical factors played a small role in underpinning daily price movements. These factors were mentioned as a driver of the market on $6.3 \%$ of trading days in the sample. 
Thus, just as the present-value model implies, market participants consider fundamental factors to be by far the main driver of stock prices. Its REH version, however, is inconsistent with the relevance of the nonfundamental factors. In Section 5, we present evidence that the vast majority of the sample's "psychology" mentions were directly connected to the market's forecasting of fundamental factors and stock prices. This evidence, together with the factor frequencies in Table 1, leads to a clear conclusion: stock prices are largely driven by fundamental factors, but not in the way hypothesized by an REH model.

\subsection{Two Main Channels: Forecasts of Dividends and Interest Rates}

The present-value model implies not only that news about fundamental factors matters for stock prices, but also that such news influences outcomes through two channels: the market's forecast of dividends and its forecast of interest rates. It is in assessing this key implication of the model that rule-based manual reading of narrative reports proves essential. Mangee's (2011) reading of Bloomberg News market wraps reveals frequent explicit mentions of news that affected stock prices through either the dividend channel or the interest rate channel. ${ }^{11}$

In Table 2, we list the categories of factors from Table 1 that Bloomberg News most often explicitly mentions as influencing the market's forecasts of dividends and interest rates. We group these categories into those that

Table 2: Explicit Mentions of Dividend and Interest Rate Forecasts:

\begin{tabular}{|c|c|c|}
\hline \multicolumn{3}{|c|}{ Main Factor Categories } \\
\hline Dividend Channel & Interest Rate Channel & Either Channel \\
\hline Dividends & Interest rates & Macroeconomic \\
\hline Company variables & Inflation rates & activity \\
\hline Sales & $\begin{array}{l}\text { Central bank } \\
\text { communication }\end{array}$ & \\
\hline
\end{tabular}

Notes: The factor categories that Bloomberg News mentions most often in moving stock prices through the dividend channel, interest rate channel, or either channel.

\footnotetext{
${ }^{11}$ See the Data Appendix for examples of such reporting.
} 
Bloomberg News explicitly connect to the dividend channel, the interestrate channel, and either channel. The list of categories in the Table is what we would expect. The market largely relies on factors concerning dividends, company variables, and sales in forecasting dividends, whereas factors concerning interest rates, inflation, and central-bank communications underpin its forecasts of interest rates. Moreover, we find that news concerning macroeconomic activity is explicitly mentioned as impacting stock prices through both channels.

\subsubsection{The Dividend Channel}

Consider first the evidence that news about dividends is interpreted by the market through the dividend channel. The dividend category in Table 1 includes mentions of firms' dividend and earnings announcements, as well earnings forecasts by firms and analysts. ${ }^{12}$ Reports that earnings forecasts moved stock prices are ipso facto explicit mentions of the market's forecasting of dividends. Moreover, as we mentioned in Section 3.2, Bloomberg journalists often report that the impact of a piece of news depends on whether a factor moved more or less than expected. Reports that relate news about factors in the dividend category to what the market had expected are also explicit mentions of the dividend channel. We find that $75 \%$ of the daily wraps in which news concerning dividend factors was reported as having driven stock prices either involved earnings forecasts or was related to the market's expectation concerning these factors.

Explicit mentions of the dividend channel also include reports that factors in the company variables and sales categories impacted the market though its forecasting of dividends. In Table 3, we report the share of trading days in the sample for which Bloomberg News explicitly mentioned the dividend channel - because of news concerning factors in the dividends, company variables, or sales categories - as underpinning stock-price movements. We find that this channel was explicitly men-

\footnotetext{
${ }^{12}$ We include mentions of earnings announcements and earnings forecasts in the dividend category because a firm's decision to pay a dividend depends on its current and future earnings potential.
} 
Table 3: Mentions of Dividend and Interest Rate Forecasts

\begin{tabular}{lccc}
\hline \hline & Explicit Mentions & Implied Mentions & Total \\
\hline Dividend channel & 46.1 & 20.7 & 61.9 \\
Interest rate channel & 25.8 & 17.8 & 38.6 \\
Either channel & 63.2 & 70.5 & 95.0 \\
\hline \hline
\end{tabular}

Notes: All figures represent the proportion of total trading days on which Bloomberg News implicitly or explicitly mentioned in the wrap reports dividend forecasts, interest rate forecasts, or either of the present value model's two channels.

tioned on $46.1 \%$ of all trading days in the sample. ${ }^{13}$

The evidence that news concerning dividend, company variables, and sales factors was explicitly mentioned as impacting stock prices through the dividend channel suggests that such news is particularly relevant for forecasting dividends. Indeed, we would expect that most such forecasts would rely on this news.

We thus consider reports that news about dividend, company variables, or sales factors drove price movements, but that do not explicitly indicate the dividend channel, as implied mentions of this channel. Table 3 reports that such implied mentions of the dividend channel occurred on $20.7 \%$ of all trading days in the sample.

When we consider explicit and implied mentions together, we find that the dividend channel was mentioned at least once as underpinning stock-price movements on $61.9 \%$ of all trading days.

Table 1 provides corroborating evidence of the importance of the dividend channel. It shows that the most important fundamental drivers of stock prices were factors in the dividend, company variables, and sales categories; these factors, along with those concerning macroeconomic activity, were mentioned, respectively, on $43 \%, 23 \%, 23 \%$, and $35 \%$ of the trading days in the sample. These factors are those that we would expect to be the most relevant for the market in forecasting dividends.

This evidence is remarkably consistent with quantitative data on

\footnotetext{
${ }^{13}$ Explicit mentions of the dividend channel occurred on $30.3 \%$ and $21.8 \%$ of all trading days in connection with the factors in the dividend category and other fundamentals, respectively. The sum of these figures is larger than the $46.1 \%$ reported in Table 3 because there are some days on which both sets of factors are mentioned.
} 
stock prices and earnings. In Figure 1, we provide simple time plots of the S\&P 500 price index and underlying earnings over Mangee's (2011) sample period. The close co-movement of the two series is striking. Not only do the broad swings in prices and earnings rise and fall together, but their major turning points in 2000, 2003, and 2007 are closely synchronized. The consistency of Bloomberg's reporting with Figure 1 provides further indication that its wrap reports provide insight into the process underpinning stock prices.

Figure 1: The S\&P500 Price Index and Company Earnings

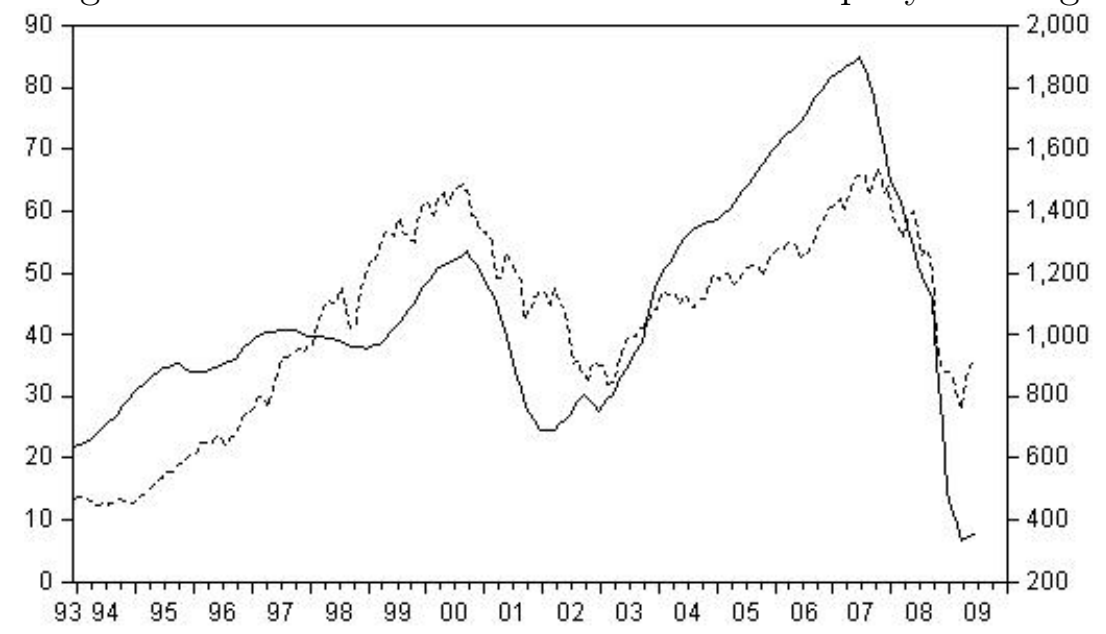

Notes: The figure plots the monthly S\&P500 Price Index (dotted line) and a monthly index of company earnings (solid line). Data are from Robert Shiller's website: http://www.econ.yale.edu/ shiller/.

\subsubsection{The Interest Rate Channel}

Mangee's evidence for the interest rate channel also involves explicit and implied mentions. The interest rate category includes news about short-term and long-term domestic interest rates. As with the dividend category, Bloomberg's reporting often relates the impact of interest rate movements explicitly to the market's forecast concerning these movements. ${ }^{14}$

The wraps also explicitly reported that news concerning the inflation rate and central bank communications impacted prices through the

\footnotetext{
${ }^{14}$ This applies to $27.1 \%$ of its interest rate mentions.
} 
market's forecasting of interest rates. Consequently, we consider reports that news about interest rate, inflation rate, or central bank factors drove price movements, but that do not explicitly indicate interest rate forecasts, as implied mentions of the interest rate channel.

Table 3 reports that this channel was mentioned explicitly and implicitly as underpinning stock-price movements on, respectively, $25.8 \%$ and $17.8 \%$ of all trading days in the sample. When we consider explicit and implied mentions together, we find that this channel was mentioned as driving stock-price movements at least once on $38.6 \%$ of all trading days.

\subsubsection{Either Channel}

Table 3 also reports the share of trading days for which news was explicitly reported to have impacted stock prices through either the dividend or the interest rate channel. We find that at least one of these two channels was explicitly mentioned on roughly two-thirds $(63.2 \%)$ of all trading days.

We reported that Bloomberg News explicitly mentioned news concerning macroeconomic factors as impacting stock prices through both the dividend and interest rate channels. We thus include in our measure of implied mentions of either channel reports that these factors drove stock prices, but that do not indicate the channel through which the impact occurred.

Table 3 reports that either the dividend or interest rate channel was implicitly mentioned at least once on $70.5 \%$ of all trading days in the sample. When explicit and implied mentions of either channel are considered together, we find that Bloomberg News mentioned at least one of the present-value model's two channels in its reporting of price movements on nearly every trading day in the sample (95\%).

\subsection{Model-Consistent Impacts}

Bloomberg's market wraps report the qualitative impact of the usual fundamental factors, such as interest rates or GDP, on stock prices. For these factors, the last column in Table 1 provides the proportion of 
positive (and thus negative) impacts.

However, several of the categories in the table encompass factors that are events that Bloomberg reports moved the market, for example, central bank communications, financial market reforms, and elections. These events are heterogeneous and to some extent unique. Although Bloomberg reports that they do have an impact, the direction of this impact is context-dependent. For example, an appointment of a new Fed chair may be interpreted positively or negatively for stock prices, depending on the historical moment of the change. As a result, these categories do not lend themselves particularly well to tracking factors' qualitative impact on stock prices over time. We therefore do not count their proportions, and use a "-" .

According to the present-value model, news which the market interprets as influencing future dividends (interest rates) leads it to bid stock prices in the same (opposite) direction. Table 1 provides evidence for these predictions. For example, the $99.5 \%$ figure for the dividend category reveals that these factors mattered positively virtually every time they were mentioned in a wrap as driving the market. The $1.9 \%$ figure for the interest rates category shows that these factors mattered negatively nearly every time they were mentioned. This evidence is highly supportive of the present-value model's predictions.

Table 1 shows that factors concerning the inflation rate (those in the inflation rate category) also mattered negatively for stock prices nearly every time they were mentioned. This finding may appear inconsistent with the present-value model, given that a change in the expected inflation rate, ceteris paribus, implies that real interest rates move in the opposite direction. However, the reporting by Bloomberg News reveals that the market understands inflation news largely through its impact on nominal interest rates: the market wraps explicitly connect $89 \%$ of inflation mentions to the market's forecasting of nominal rates.

The high proportion of factors in the company sales category that had a positive impact $(91.3 \%)$ is also consistent with the present-value model's predictions. We would expect, for example, that the market would interpret expanding company or industry sales largely as positive 
news for future dividends.

By contrast, $69.2 \%$ (30.8\%) of mentions of macroeconomic activity had a positive (negative) impact on prices. This finding provides evidence that the market interpreted these factors through both channels.

\section{Structural Change}

We have found the present-values model's qualitative predictions concerning stock prices' co-movements with the market's forecasts of dividends and interest rates to be consistent with textual evidence in Bloomberg's market wrap reports. Earlier studies, notably Shiller (1981) and Campbell and Shiller (1988a,b), have tested these predictions indirectly by specifying the market's forecasts in terms of a set of fundamental variables and deriving the model's quantitative implications for regularities in time-series data. These studies did not allow for quantitative change, but later studies have. ${ }^{15}$ The important study by Barsky and Delong (1993) allowed for such change and found that it improved the presentvalue model's ability to account for stock-price movements in terms of fundamental factors.

Mangee's data set provides evidence of the importance of structural change in driving outcomes in equity markets. Some of this evidence is highly suggestive. However, despite being qualitative, Bloomberg's wraps also provide explicit evidence of quantitative change in the relationship between stock prices and available information.

We saw in equation (1) that according to the present-value model, stock-price movements stem not only from news about fundamental factors, but also from market participants' revisions of how they interpret this news in forecasting outcomes. These revisions, in turn, imply quantitative structural change in the process underpinning stock prices.

To see this, we characterize the market's forecast of dividends and the interest rate in each period in terms of available information on a set of fundamental factors as follows:

$$
\mathcal{F}_{t}^{\mathrm{M}}\left[(1-\rho) d_{t+1+k}-r_{t+1+k} \mid v_{t}\right]=\beta_{t}^{k} v_{t} \ldots \text { for any } t
$$

\footnotetext{
${ }^{15}$ For example, see Driffill and Sola (1998) and Gutierrez and Jesus Vazquez (2004).
} 
where each element in the row vector $\beta_{t}^{k}$ represents how the market interprets available information on the corresponding factor in the column vector $v_{t}$ in forecasting outcomes in period $k$. This simple characterization enables us to relate the stock price in (2) to available information in period $t$ :

$$
p_{t}=\beta_{t} v_{t} \ldots \text { for any } t
$$

where each element in $\beta_{t}$ is the discounted sum of the individual $\beta_{t}^{k}$ 's that are used in representing the market's forecasts at different horizons. Over time, market participants' revisions lead to quantitative change in how stock prices are related to available information:

$$
\Delta p_{t+1}=\Delta \beta_{t+1} v_{t+1}+\beta_{t} \Delta v_{t+1} \ldots \text { for any } t
$$

where $\Delta \beta_{t+1} v_{t+1}$ represents the structural change effects and $\beta_{t} \Delta v_{t+1}$ represents informational effects on prices.

Shiller (1981) and most other empirical studies of the REH presentvalue model rule out unanticipated structural change by constraining $\Delta \beta_{t+1}=0$ in every time period. ${ }^{16}$ According to these time-invariant models, stock-price movements are driven solely by the arrival of information on the relevant fundamental factors.

However, Bloomberg's market wraps provide ample evidence that participants revise their forecasting strategies, that is, $\beta_{t}$ changes over time. These revisions, in turn, lead to quantitative change in the process underpinning stock prices.

\subsection{Change in the Set of Relevant Fundamentals}

Mangee's data enables us to examine fluctuations in the frequency with which a factor was mentioned as relevant for moving stock prices. In Figures 2-5, we plot 12-month moving averages of the proportion of days per month that news about dividends, interest rates, inflation rates, and

\footnotetext{
${ }^{16}$ For example, researchers often formalize the processes underpinning dividends and the interest rate in all time periods as random walks. $\mathrm{REH}$ then implies that $\beta=$ $\left[1, \frac{1}{1-\rho}, \frac{-1}{1-\rho}\right]$ and $v_{t}^{\prime}=\left[d_{t}, \mu, r_{t}\right]$, where $\mu$ denotes the constant drift for dividends.
} 
oil prices, respectively, was mentioned by Bloomberg News as driving the market (the solid lines in the figures).

The fluctuations in the figures may not be indicative of quantitative revisions of forecasting strategies. They could simply arise because the value of the factor itself varies over time. One important reason is that small movements in a factor may lead to small movements in the market. These small movements might attract little attention and go unreported by Bloomberg News. ${ }^{17}$ However, comparison of fluctuations in the monthly frequencies of Bloomberg's mentions of a factor with the actual movements in that factor (the dotted lines in the figures) strongly suggest that at least some of the fluctuations in the Figures involve quantitative structural change in the impact of factors on stock prices $-\Delta \beta_{t+1} v_{t+1}$.

Consider the monthly frequency for factors in the dividend category in Figure 2. In the 1995-1998 period, there were relatively small movements in actual earnings but large swings in the frequency of mentions of factors in this category. The large upswing in actual earnings that began in 2002 was associated with relatively little fluctuation in the frequency of Bloomberg mentions.

The frequency measures for the other two categories of fundamental factors show even more dramatic fluctuations. The frequency of interestrate mentions in Figure 3 fluctuated sharply, from 30\% to 50\%, during 1993-1996, despite a time path for actual interest rates that was sloping downward only moderately.

Beginning in 1997, the interest rate frequency experienced a dramatic fall, from $50 \%$ to essentially zero by 2001 . It remained near zero during 2001-2004. These fluctuations indicate that during the first part of our sample, the market relied on interest rate factors in forecasting outcomes, whereas it largely ignored these factors in 2001-2004.

Similar fluctuations involving monthly frequencies plunging to near

\footnotetext{
${ }^{17}$ Fluctuations in monthly frequencies of mentions could also arise from variation in the frequency with which news about a factor became available to the market. But this explanation of fluctuations in the monthly frequencies is implausible, because news about dividends, interest rates, and inflation rates is reported by all of the major business news outlets regularly throughout every month of our sample.
} 
Figure 2: Dividends

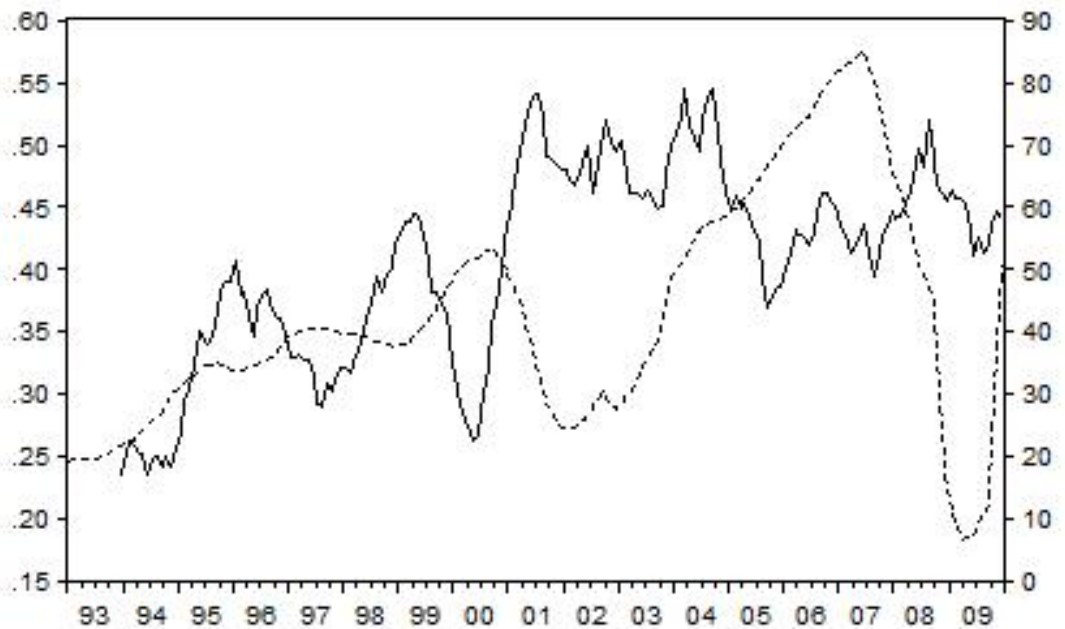

Notes: The figure plots the 12-month moving average of the monthly frequency with which Bloomberg News mentions factors in the dividend category as moving stock prices (solid line) and a monthly index of actual company earnings (dotted line). The data for company earnings are from Robert Shiller's website: http://www.econ.yale.edu/ shiller/.

Figure 3: Interest Rates

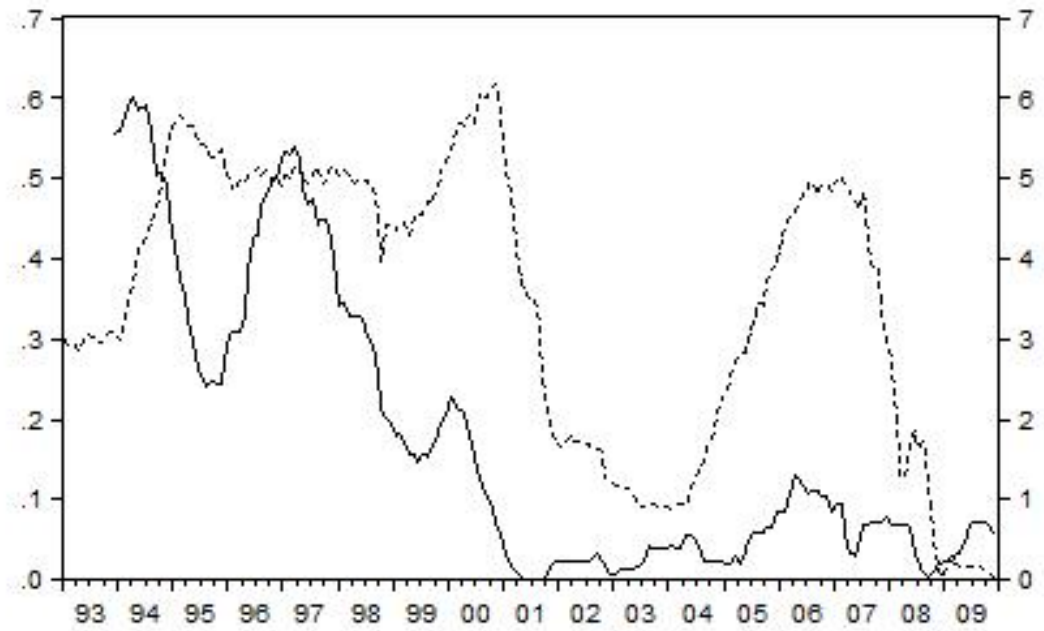

Notes: The figure plots the 12-month moving average of the monthly frequency with which Bloomberg News mentions factors in the interest rate category as moving stock prices (solid line) and the actual 1-month Treasury bill rate (dotted line). The data for the 1-month Treasury bill rate are from the Federal Reserve Economic Database. 
zero or rising sharply from such a level, despite large variation in a factor can also be seen in Figures 4 and $5 .^{18}$

\section{Figure 4: Inflation Rates}

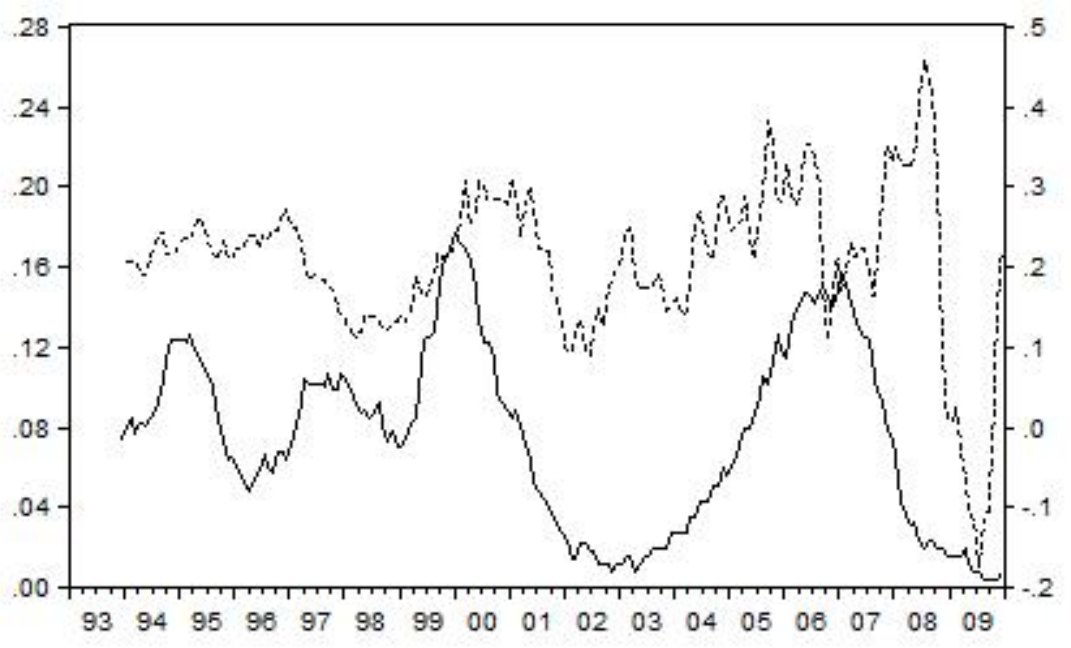

Notes: The figure plots the 12-month moving average of the monthly frequency with which Bloomberg News mentions factors in the inflation rate category as moving stock prices (solid line) and the monthly percent change in the actual Consumer Price Index (dotted line). The data for the Consumer Price Index are from the Federal Reserve Economic Database.

Our finding that the market sometimes ignores news about interest rate factors in forecasting outcomes raises a question concerning the relevance of the present-value model's interest rate channel for understanding stock-price fluctuations. In Figure 6, we plot the same monthly frequency for interest rate factors as in Figure 3, along with the monthly frequency for all other fundamental factors that Bloomberg News mentioned in its market wraps as influencing stock prices through the interest rate channel.

We see that during the 2001-2002 period, the near-zero interest rate frequency occurred alongside a much higher frequency of mentions of other fundamentals. The large upswings in these mentions during 1995-

\footnotetext{
${ }^{18}$ For example, during 2002, the monthly frequency for inflation rate factors fell to near zero, even though the actual inflation rate more than doubled, from $.1 \%$ to above . $2 \%$. Similarly, the monthly frequency for oil prices remained largely below $5 \%$ from 1999 to 2003 , despite rising oil prices from $\$ 26.1$ in December 1998 to $\$ 98.8$ in November 2000 and falling back to $\$ 45.4$ by December 2001 .
} 
Figure 5: Oil Prices

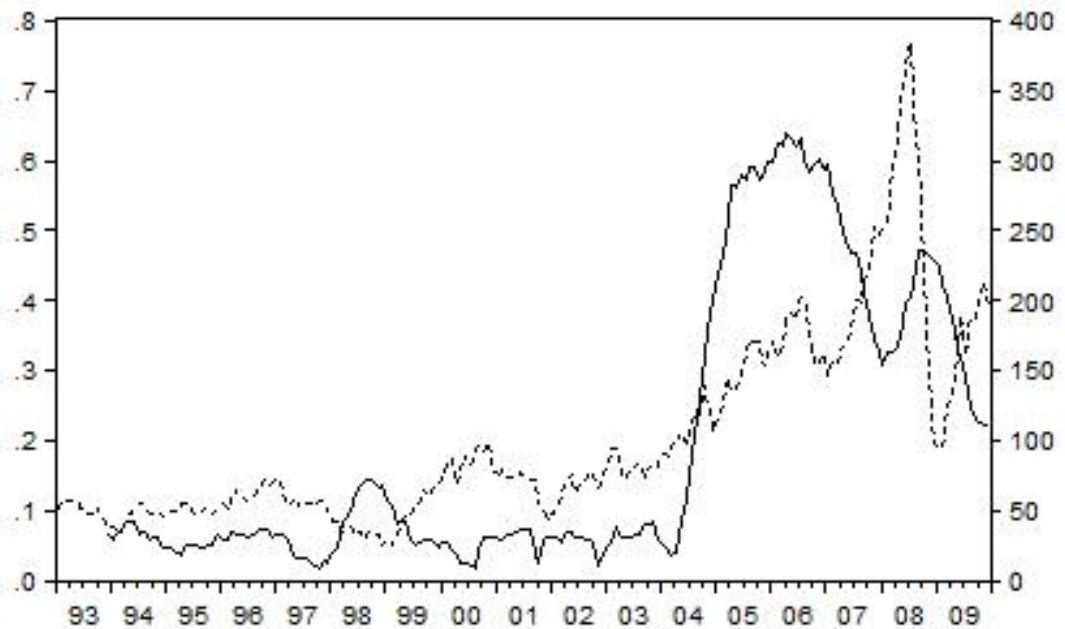

Notes: The figure plots the 12-month moving average of the monthly frequency with which Bloomberg News mentions oil prices as moving daily stock prices (solid line) and the actual price of domestic crude petroleum (dotted line). The data for the oil price are from the Bureau of Labor Statistics.

Figure 6: The Interest Rate Channel

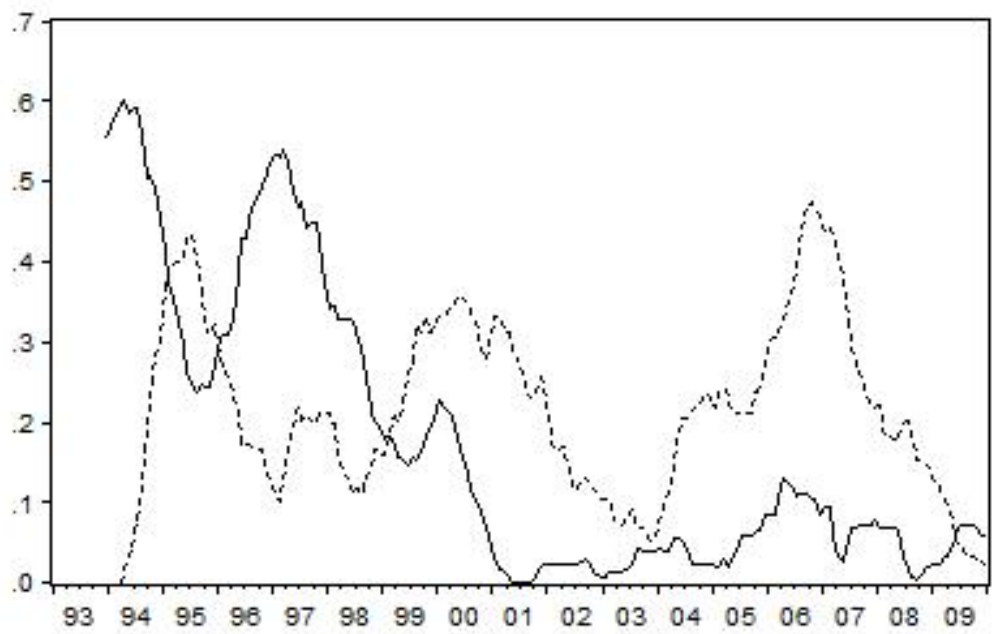

Notes: The figure plots 12-month moving averages of the monthly frequency of explicit and implicit mentions of the interest rate channel stemming from news concerning interest rates (solid line) and all other fundamental factors (dotted line). 
1999 and 2004-2006 indicate substantial changes in the set of variables that the market considered relevant for forecasting interest rates. Indeed, the tendency for the two series to move in mirror fashion suggests that when the market relies less (more) on one fundamental in forecasting, it increases (decreases) its reliance on other fundamentals.

Figure 7 provides analogous time plots for the dividend channel. We again see large fluctuations in the frequency of explicit mentions of this channel stemming from news about factors other than those in the dividend category (for example, the sharp upturn in 1994-95).

Figure 7: The Dividend Channel

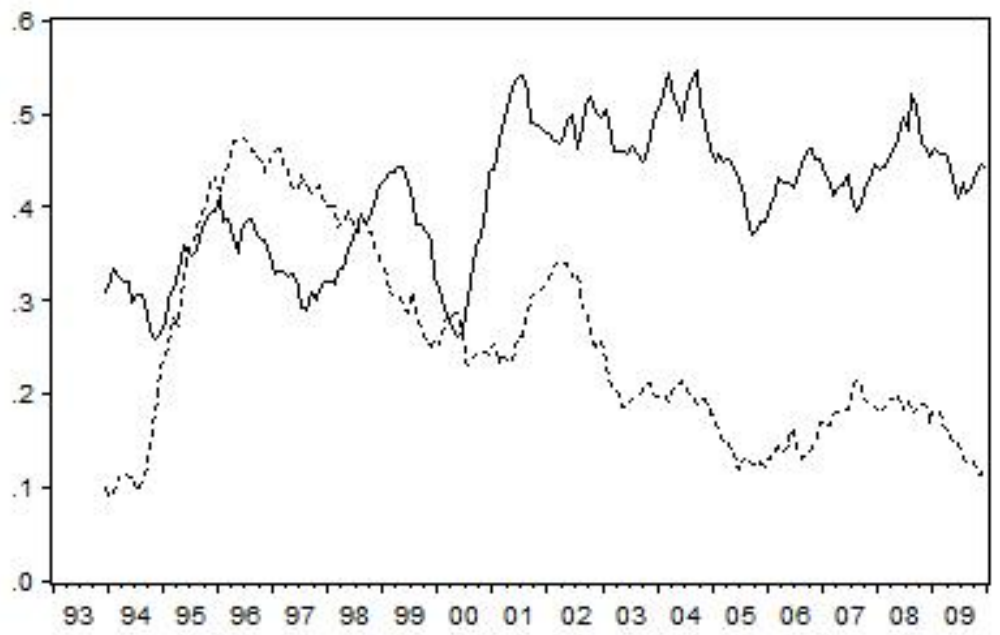

Notes: The figure plots 12 -month moving averages of the monthly frequency of explicit and implicit mentions of the dividend channel stemming from news concerning dividends (solid line) and all other fundamental factors (dotted line).

Taken together, Figures 2-7 indicate that the process underpinning stock prices not only undergoes structural change, but that this change takes on a striking form: different fundamental factors are relevant for the market during different time periods.

Evidence of changes in the composition of relevant fundamental factors is also provided in Figure 8, which plots the average number of fundamental factors that the Bloomberg wraps report underpin stockprice movements each day in a month. 
Figure 8: Change in the Number of Relevant Fundamental Factors

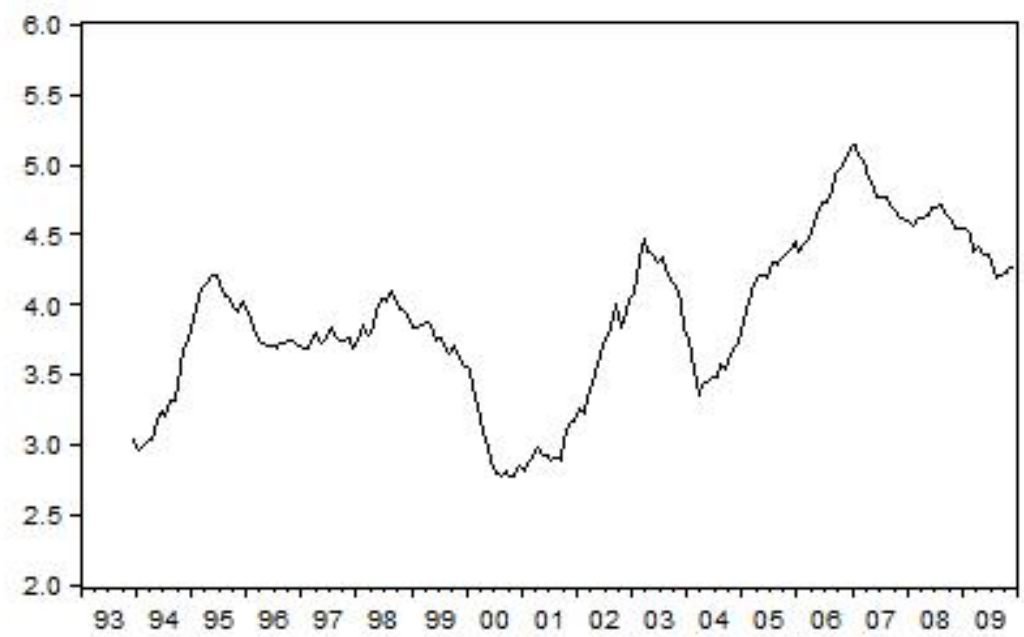

Notes: The figure plots the average daily number of separate fundamental factors that Bloomberg reported moved stock prices in a month. The figure is based on a 12-month moving average.

As we can see, this number rose from three to higher than four during 1993-1994, and remained roughly four for most of the 1990s. After falling back to three during 2000-01, the number of relevant fundamental factors rose to an average of 4-5 by 2006 and remained at this level through the end of the sample.

\subsection{Explicit Evidence on Quantitative Structural Change}

Mangee's data set also provides explicit evidence on the quantitative structural change in equity markets. This evidence comes from reports of switches in the sign of the impact of news on stock prices.

By far the most important among these factors are those in the macroeconomic activity category, which was mentioned as relevant on $35 \%$ of the trading days. We reported in Section 4.2 that the market interpreted news on overall economic activity through both the dividend and interest rate channels, with positive and negative impacts, respectively. Thus, whenever this news matters positively (negatively) for stock prices, its impact through the dividend channel is greater (smaller) 
in magnitude than its impact through the interest rate channel. Consequently, our finding that the impact of news about the macroeconomic activity was positive on $69.2 \%$ of the days on which this news was mentioned and negative on $31.8 \%$ of the other days provides explicit evidence of quantitative structural change (see Table 1).

News-impact studies have uncovered a similar finding of structural change in the impact of macroeconomic news on stock prices, lending further support to the value of Mangee's evidence. ${ }^{19}$ These studies report that good news about macroeconomic activity impacted stock prices negatively during expansions and positively during contractions.

However, Bloomberg News reporting indicates that these sign shifts are not as closely connected to the economic cycle. This looser connection can be seen in Figure 9, which plots the proportion of mentions each month for which news about macroeconomic activity mattered positively for stock prices. ${ }^{20}$ Shaded regions in the Figure denote periods of economic contraction, the dating of which is determined by the National Bureau of Economic Research (NBER). A figure above 50\% (below 50\%) indicates that good news about macroeconomic activity was interpreted by the market largely as positive (negative) news for stock prices.

We see that this proportion exceeded $50 \%$ during the two periods of economic contraction (denoted by the shaded regions in the figure). Moreover, the proportion of negative mentions was mostly above $50 \%$ during much of the 1990s economic expansion. These findings are consistent with those of the news-impact studies. However, there were two intervals during this expansion, each lasting roughly a year, for which the proportion of positive mentions was largely above $50 \%$. Table 1 shows that the impact of oil prices and currency-market factors also involved switches in sign over the period of the sample. These sign switches, as with those involving news about macroeconomic activity, provide explicit evidence of quantitative structural change in the process underlying stock prices.

\footnotetext{
${ }^{19}$ See, for example, Pearce and Roley (1985), McQueen and Roley (1993), Fair (2002), Boyd et al. (2005), and Andersen et al. (2007).

${ }^{20}$ We again use a 12 -month moving average.
} 
Figure 9: Change in the Qualitative Impact of Macroeconomic Activity

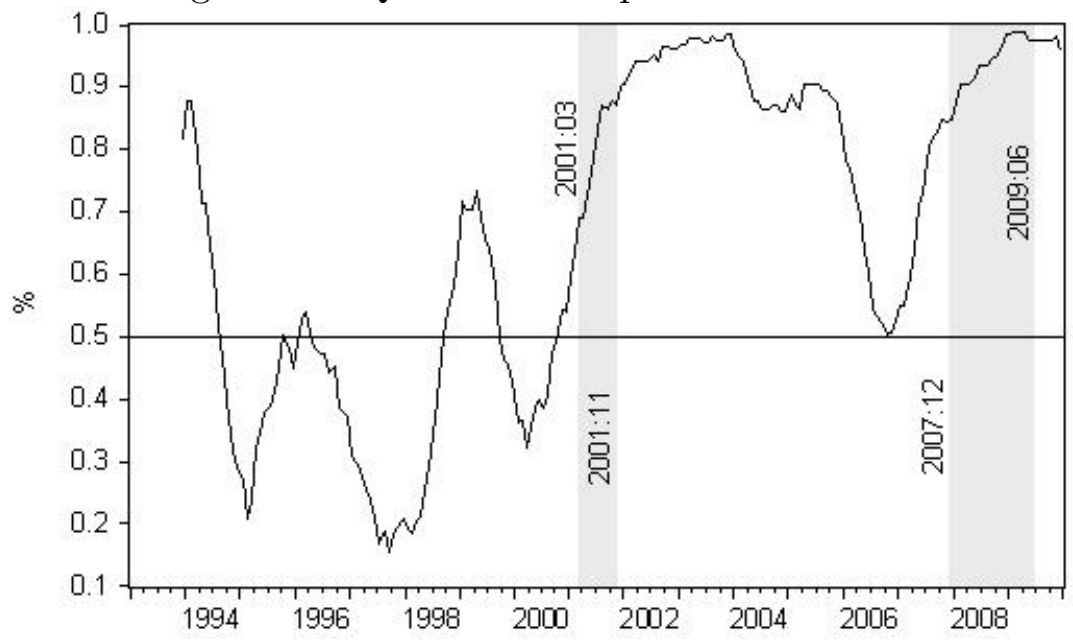

Notes: The figure plots the proportion of mentions per month involving macroeconomic activity for which Bloomberg News reports a positive qualitative impact on stock prices. The figure is based on a 12-month moving average. The shaded regions denote recessions based on the NBER Dating Committee.

\subsection{Could Structural Change Have Been Known $\boldsymbol{E x}$ Ante?}

As any good forecaster of macroeconomic activity knows, shifts in the economic cycle are often triggered by events that, even in the best cases, can be only dimly anticipated. We would therefore expect that the quantitative structural change documented by the news-impact studies and Bloomberg News market wraps would be all but impossible to foresee, even in probabilistic terms.

Indeed, members of the NBER's Business Cycle Dating Committee often disagree on the timing of when a cycle begins or ends, even though they have access to ex post data. To put it simply, structural change is often triggered by events that are not exact repetitions of similar events in the past. As unique events, they are difficult to time precisely, and their quantitative effect on change in the economy's structure depends on the extent of their novelty and the particular historical context in which they occur. These obstacles to understanding change that occurred in the past pale in comparison with the difficulties inherent in forecasting change yet to come. 
The appointment of Paul Volcker to lead the U.S. Federal Reserve is just one of many examples. Few could have foreseen in 1978 that he would be appointed in 1979. In order to have foreseen fully the consequences of his appointment for the subsequent movement of stock prices, one would have had to come up with a precise estimate of the severity of the contractionary monetary policy that he ultimately implemented. One would also have had to estimate a model that related these prices to the monetary-policy stance. The very fact that Volcker's change in policy was unusual, and that its impact was context-dependent, implies that there was no past data that one could have used to estimate the precise impact of Volcker's appointment ex ante.

Researchers sometimes estimate models of asset prices that allow for quantitative structural change. In a seminal paper, Hamilton (1988) formulated a class of such models. This class supposes that there are several different regimes in which prices are related to a set of factors. Hamilton represents these factors (and the error terms) in each regime with a different probability distribution and supposes that the timing of switches between regimes is governed by a Markov rule. Many researchers have estimated these models in asset markets on the basis of ex post data.

The key question is whether the estimated models would be relevant in representing asset prices in the future. Many studies constrain transition probabilities to be fixed. However, events such as the appointment of a Fed chair and the subsequent change in monetary policy are likely to render prior estimates of these probabilities inadequate. ${ }^{21}$ Indeed, Bloomberg News reports that many of the fundamental factors that move stock prices involve events that are to some extent novel and whose impact is context-dependent.

In Table 4, we list the categories of fundamental factors from Table 1 that involve such historical events, which include wars, election outcomes, and other major geopolitical developments. We find that such

\footnotetext{
${ }^{21}$ For an early argument along these lines in the context of currency markets, see Kaminsky (1993). She finds that the transition probabilities underpinning regime switches are not only time-varying, but that they also depend on who is Fed chair and the credibility of the incumbent's policies.
} 
events account for a substantial fraction (roughly 20\%) of Bloomberg's mentions of fundamental factors over the sample.

Table 4: Historical Events that Moved the Market

\begin{tabular}{lc}
\hline \hline Mergers and acquisitions (435) & Fed comments/Fed minutes/ \\
Legal or Accounting Issues (286) & other Fed communication (369) \\
Leverage/credit issues (159) & Communication by government \\
Armed conflicts (143) & officials (151) \\
Bailouts or nationalization & Business spending (63) \\
of banks (90) & Political conflict, instability, \\
Liquidity issues (59) & corruption (55) \\
Management Shake-ups (47) & Macroprudential policy (40) \\
Bankruptcy (45) & Purchases of large stake/ \\
Fiscal policy/stimulus plan (40) & stock splits/share buybacks (38) \\
Trade agreements (30) & Political elections (22) \\
Labor layoffs or strikes (25) & Financial reform (19) \\
Terrorism (21) & Natural disasters (11) \\
Initial Public Offerings (18) & Cabinet changes (3) \\
Healthcare policy (11) & Taxes or rules on CEO bonuses (1) \\
Tariff/quotas/subsidies (3) & Introduction of Euro (1) \\
\hline \hline
\end{tabular}

Notes: The table lists the fundamental factors from Table A1 that involve historical events that are to some extent unique. Figures in parentheses denote the total absolute number of mentions for each factor.

Consider, for example, the following excerpt from a wrap report from March 31, 2003: "U.S. stocks fell for a fourth straight day on concern that the war in Iraq may last for months and already is curbing business spending." Few could have anticipated before September 11, 2001, that the U.S. would be in a land war in Iraq in 2003, let alone how the war and fall of business spending could have altered the process underpinning dividends and stock prices in the future.

\section{Why Has the REH Present-Value Model Failed?}

Shiller and other behavioral-finance economists did not relate the failure of the REH present-value model to the importance of unanticipated structural change in driving outcomes. Having ignored such change, they retained REH - which rules out any role for psychological factors in rational forecasting - as the only way to represent how a rational, 
profit-seeking participant forecasts outcomes in terms of fundamental factors. ${ }^{22}$

This has led behavioral-finance economists to interpret the REH model's empirical failure as evidence that the market is dominated by individuals who are not "fully rational" (Barberis and Thaler, 2003, p. 1056). Their "bubble" models suppose that these individuals' forecasts - and thus stock prices - are driven by psychological and other non-fundamental factors that are largely unrelated to fundamental considerations

But there is an alternative explanation of the REH present-value model's empirical difficulties: unanticipated structural change is an important driver of outcomes in real-world markets, and a rational, profitseeking participant recognizes this. ${ }^{23}$ Consequently, in real-world markets there are many ways to understand future outcomes in terms of fundamental factors. In order to select a forecasting strategy that relates stock prices to information about fundamental factors, a participant must rely on psychological and other non-fundamental factors. We would expect that whenever market participants mention psychological factors, they would relate them to their understanding of how fundamental factors would drive future outcomes.

This is borne out by the Bloomberg News market wraps, which provide rather strong evidence against the behavioral theorists' interpretation of the REH present-value model's empirical difficulties - and rather strong support for our own.

\subsection{Fundamentals and Psychology in Rational Fore- casting}

Even cursory observation suggests that participants in real-world markets revise their forecasting strategies at times and in ways that they

\footnotetext{
${ }^{22}$ As Sargent (2005, p.566) acknowledged, "The fact is that [one] cannot talk about ..differences [among people's models] within the typical rational expectations model. ..All agents inside the model, the econometrician, and God share the same model."

${ }^{23}$ This interpretation of REH models' empirical failures builds on Knight's (1921, p. 198) fundamental insight. As he put, "it is our imperfect knowledge of future ...change, not change as such, which is crucial to the understanding" of how profitseeking market participants make decisions.
} 
could not have anticipated in advance. We have seen that reporting by Bloomberg News is consistent with this seemingly uncontroversial observation. The importance of unanticipated change in how outcomes unfold over time implies that both fundamental and psychological factors play a role in participants' forecasting. A rational participant understands that there are many ways to forecast; thus, he cannot rely solely on statistical analysis or other calculations to ascertain which forecasting strategy he should use. Ultimately, he is guided by the confidence that he has in choosing one strategy over others to relate available information on fundamental factors to future outcomes. As a result, intuition and emotions (such as optimism and fear) inevitably play a role in how a rational, profit-seeking participant chooses his forecasting strategy and when and how to revise it.

Table 1 shows that psychological factors do indeed play an important role in underpinning market movements; on average, they were explicitly mentioned as having driven prices on roughly every other day. Remarkably, however, we find that $98.5 \%$ of all psychology mentions were reported as having impacted stock prices through the market's forecasting of fundamental factors. These findings, together with the evidence that the price process undergoes unanticipated structural change, supports our non-bubble explanation of the role of psychological and other non-fundamental factors in real-world markets.

REH models rule out quantitative change in the economy's structure that an economist did not fully specify in advance. The evidence that such unanticipated structural change underpins stock-price movements leads us to a novel explanation of the REH present-value model's empirical failure: participants in real-world markets are rational. They know that they cannot afford to ignore such change. Eventually, they revise their forecasting strategies at times and in ways that an REH theorist could not specify in advance. Such unanticipated revisions render the REH present-value model's account of stock-price movements inconsistent with time-series data, as Shiller and many others have found. ${ }^{24}$

\footnotetext{
${ }^{24}$ Frydman and Goldberg (2015) provide a rigorous demonstration of this argument in the context of the present-value model.
} 


\section{Data Appendix}

This appendix consists of three sections. We first report the set of rules Mangee (2011) uses in extracting relevant information contained in Bloomberg market wraps and converting this information into numerical data. We then list the complete set of factors that underpinned stock prices during his sample. Finally, we consider several of Bloomberg News's market wraps to illustrate how they report on the importance of fundamental, psychological, and technical factors and how Mangee scores these wraps. In doing so, we provide examples of explicit and implied mentions of the dividend and interest rate channels.

\subsection{Rule-Based Reading}

In what follows, we denote by $Z$ a fundamental, psychological, or technical factor and by $P$ either the Dow Jones Industrial, Standard and Poors 500, or NASDAQ price index.

\section{Recording the Relevance of $Z$}

Mangee records a 1 for $Z$ and 0 otherwise on a given day if:

1. $Z$ is mentioned as underpinning the day's $P$ movement;

2. a forecast of $Z$ is mentioned as underpinning the day's $P$ movement;

3. $Z$ is mentioned as underpinning a single firm's stock price and this movement is in the same direction as the overall market;

It is often the case that one fundamental factor is mentioned as underpinning a day's $P$ movement because it influenced the market's forecast of another fundamental factor. For these mentions, a 1 is recorded for both factors according to rules 1 and 2 .

\section{Recording the Qualitative Impact of Fundamentals}

The qualitative relationship between $Z$ and $P$ is determined by the following criteria: 
A "+" is recorded for a fundamental factor for any of the following five cases:

a. $Z$ increases(decreases) and $P$ increases(decreases);

b. $Z$ increases by more than expected and $P$ increases;

c. $Z$ decreases by more than expected and $P$ decreases;

d. $Z$ increases but by less than expected and $P$ decreases;

e. $Z$ decreases but by less than expected and $P$ increases.

A "-" is recorded for a fundamental factor for any of the following five cases

f. $Z$ increases(decreases) and $P$ decreases(increases);

h. $Z$ increases by more than expected and $P$ decreases;

i. $Z$ decreases by more than expected and $P$ increases;

j. $Z$ increases but by less than expected and $P$ increases;

k. $Z$ decreases but by less than expected and $P$ decreases. 


\subsection{The Factors that Moved the Market}

\begin{tabular}{|c|c|}
\hline Macroeconomic Activity & Company Variables \\
\hline GDP growth & Bankruptcy \\
\hline $\begin{array}{l}\text { Index of leading economic } \\
\text { indicators }\end{array}$ & $\begin{array}{l}\text { CEO or CFO changes } \\
\text { Legal or accounting issues }\end{array}$ \\
\hline Industrial production & Firm added to index \\
\hline Productivity & IPOs \\
\hline Personal income & Business spending \\
\hline Service sector activity & Mergers and acquisitions \\
\hline Employment & Book-to-bill ratio \\
\hline Unemployment rate & Labor layoff or strike \\
\hline Jobless claims & Purchase of large stake \\
\hline $\begin{array}{l}\text { Retail sales national level } \\
\text { Manufacturing activity }\end{array}$ & Stock split/Share buyback \\
\hline Factory orders & Central Bank Communication \\
\hline Durables output & Minutes \\
\hline Nondurables output & Comments by officials \\
\hline Construction spending & Macroprudential policy \\
\hline Consumer spending & \\
\hline Consumer confidence & $\frac{\text { Oil }}{\text { Crude oil prices }}$ \\
\hline \multicolumn{2}{|l|}{ Interest Rates } \\
\hline Federal Funds & $\underline{\text { Financial Institutions }}$ \\
\hline Discount & Leverage or credit \\
\hline Treasury bill & issues \\
\hline Treasury note & Liquidity issues \\
\hline Treasury bond & $\begin{array}{l}\text { Credit card defaults } \\
\text { Credit ratings }\end{array}$ \\
\hline$\frac{\text { Inflation Rates }}{\text { Producer Prices }}$ & Capital funding \\
\hline Consumer Prices & Currency Markets \\
\hline Manufacturing Prices & Exchange rates \\
\hline GDP Deflator & Introduction of Euro \\
\hline \multicolumn{2}{|l|}{ Employment Cost } \\
\hline Dividends & $\frac{\text { Sales }}{\text { Firm or industry revenues }}$ \\
\hline$\frac{1}{\text { Earnings announcements }}$ & $\begin{array}{l}\text { Firm or industry revenues } \\
\text { Auto Sales }\end{array}$ \\
\hline Earnings forecast announcements & \\
\hline Dividend announcements & International Trade \\
\hline Benchmark Valuation & $\begin{array}{l}\text { Trade agreements } \\
\text { Tariffs }\end{array}$ \\
\hline $\begin{array}{l}\text { Gap from benchmark } \\
\text { levels }\end{array}$ & $\begin{array}{l}\text { Quotas } \\
\text { Subsidies }\end{array}$ \\
\hline Overvalued & Current account balance \\
\hline Undervalued & \\
\hline
\end{tabular}


Table A1: Continued

\begin{tabular}{ll}
\hline \hline Housing & Government/Fiscal \\
\cline { 2 - 2 } $\begin{array}{l}\text { Housing starts } \\
\text { Foreclosures }\end{array}$ & $\begin{array}{c}\text { Fiscal policy/stimulus plan } \\
\text { Comments by officials }\end{array}$ \\
Home prices & Taxes or rules on CEO \\
Real estate prices & bonuses \\
Commercial prices & Bailout or nationalization \\
Mortgage rates & of banks \\
Geopolitical Issues & Health care issues \\
Armed conflicts & Budget surplus or deficit \\
Nuclear testing & Political elections \\
Terrorism & Political conflicts, \\
Rest of World & instability or corruption \\
All of the above factors & Cabinet changes \\
as they pertain to the & \\
rest of the world & \\
\hline \hline
\end{tabular}

Notes: Each category includes fundamental factors that Bloomberg News reported in at least one market wrap moved daily stock prices. GDP, Gross Domestic Product; CEO, chief executive officer; CFO, chief financial officer; IPO, initial public offering. See Mangee (2011) for more detail on factor definitions.

\begin{tabular}{ll} 
Table A2: Psychological Factors \\
\hline \hline Optimism & Concern \\
Pessimism & Euphoria \\
Confidence & Crowd psychology \\
Sentiment & Exuberance \\
Greed & Worry \\
Fear & Panic \\
\hline \hline
\end{tabular}

Notes: Psychological factors that Bloomberg News reported in at least one market wrap moved daily stock prices. See Mangee (2011) for more detail on factor definitions.

Table A3: Technical Factors

\begin{tabular}{ll}
\hline \hline Non-momentum & Momentum \\
\cline { 2 - 2 } Profit taking & Market rally \\
Firm added to index & Market momentum \\
Holiday effect & Momentum traders \\
January effect & Bandwagon \\
End of month effect & Price-to-price loop \\
End of quarter effect & Moving average \\
Friday effect & Chartism \\
End of year effect & \\
Giving back effect & \\
Triple witching & \\
Monday effect & \\
\hline \hline
\end{tabular}

Notes: Technical factors that Bloomberg News reported in at least one market wrap moved daily stock prices. See Mangee (2011) for more detail on factor definitions.

\subsection{Bloomberg New's Reporting}

We first provide examples of how Bloomberg News reports on the importance of fundamental factors and how Mangee scores them. 


\subsubsection{The Dividend Channel}

Consider the following excerpt from a market wrap:

"U.S. stocks rallied, sending the Dow Jones Industrial Average and Nasdaq Composite Index to their biggest gains this year, after International Business Machines Corp.'s earnings beat forecasts." [January 14, 2008]

The excerpt explicitly mentions the dividend channel, since it reports the impact of earnings relative to what the market expected. According to scoring rules 1 and b, a "+1" would be scored for earnings on the given day.

This next explicit mention of the dividend channel involves news concerning a factor other than those in the dividend category:

"The U.S. stock market posted its first advance in four days after a rally in oil prices improved earnings prospects for fuel producers and better-than-expected profit at Oracle Corp. ignited shares of software makers." [June 27, 2007]

According to scoring rules 1 and 2, a " +1 " would be recorded for both oil prices and earnings on the given day.

The last excerpt we consider involves disappointing news about macroeconomic activity that, as we discussed in section 4.2 , is an implied mention of the dividend channel:

"U.S. stocks fell after a government report showed weakerthan-expected economic growth. The U.S. economy cooled to a 3.1 percent annual rate of growth in the final three months of last year from 4 percent in the third quarter, the Commerce Department said. Economists expected a 3.5 percent expansion, according to the median estimate in a Bloomberg News survey." [January 28, 2005]

According to scoring rules 1 and $\mathrm{j}$, a " +1 " would be recorded for macroeconomic activity on the given day. 


\subsubsection{The Interest Rate Channel}

The following excerpt explicitly mentions news about interest rates as impacting stock prices through how the market forecasts interest rates:

"U.S. stocks rose for a fourth day after the Federal Reserve cut its benchmark interest rate more than forecast to help revive the economy." [November 6, 2002]

Scoring rules 1 and f imply a " -1 " for interest rates.

This next explicit mention of the interest rate channel involves news concerning a factor other than those in the interest rate category:

"U.S. stocks fell as an unexpected drop in jobless claims rekindled concern that inflation may accelerate, prompting the Federal Reserve to keep raising interest rates." [February $23,2006]$

In scoring this excerpt, Mangee records a " +1 " for jobless claims (rules 1 and a) and " -1 " for both inflation and interest rates (rules 2 and f).

The last excerpt we consider involves interest rate news without explicitly mentioning expectations. As we discussed in section 4.2 , it is an implied mention of the interest rate channel.

"U.S. stocks suffered their worst slide in more than six weeks as bond yields surged. Coca- Cola Co. and bank shares led the decline. 'It's no longer a continuing flow of good news,' said John Niedenberger, who helps oversee $\$ 3.5$ billion as a money manager with Advanced Investment Management in Pittsburgh. 'Any time rates go up stock investors get nervous, because higher rates cause investors to value stocks lower.' [August 8, 1997]

Scoring rules 1 and f imply a " -1 " for interest rates. 


\subsubsection{Psychological Factors}

The last two excerpts in the preceding section show how Bloomberg News often reports on the importance of psychological factors: they relate these factors to how market participants interpret the impact of news concerning fundamental factors. In scoring these wraps, Mangee would record a "1" for "concern" on February 23, 2006 and a "1" for "nervous" on August 8, 1997 (scoring rule 1).

This next excerpt provides another example of such reporting:

"U.S. stocks rose for a second day, after Federal Reserve Chairman Alan Greenspan fueled optimism for a growing economy and higher company profits." (July 23, 1997)

Scoring rule 1 implies a " 1 " for optimism.

The last excerpt we consider shows how Bloomberg reports on the importance of pure psychology factors (that is, which are not mentioned explicitly in connection with interpreting the influence of news about fundamental factors for stock prices):

"U.S. stocks slid...'This is what happens when the contagion of fear spreads,' said Quincy Krosby, who helps manage about $\$ 380$ billion as chief investment strategist at the Hartford in Hartford, Connecticut." [October 9th, 2008]

Scoring rule 1 implies a "1" for fear.

\subsubsection{Technical Factors}

The technical factors listed in Table A3 are grouped into two categories: those that behavioral models emphasize, which involve some type of momentum or bandwagon trading, and those that are unrelated to such trading. The following two excerpts illustrate how Bloomberg News reports on the importance of these two types of factors, respectively:

"U.S. stocks rose as...some of the buying came from 'momentum' traders, who buy stocks that are going up in order to realize a quick gain. 'It's just money chasing stocks at 
this point, anticipating the market making a new high and then carrying forward on its own momentum,'said Joseph DeMarco, head of trading at HSBC Asset Management Americas Inc." [July 8, 1998]

"U.S. stocks rose...[t]he so-called January effect was in evidence as communications equipment stocks, the worst-performing group in the major indexes last year, rose." [January 3, 2002]

Scoring rule 1 implies a " 1 " for both market momentum and momentum traders on July 8, 1998, whereas on January 3, 2002, it implies a "1" for the January effect. 


\section{References}

Andersen, Torben G., Tim Bollerslev, Francis X. Diebold and Clara Vega (2007), "Real-Time Price Discovery in Global Stock, Bond and Foreign Exchange Markets," (August 16, 2007). CREATES Research Paper No. 2007-20.

Antweiler, Werner and Murray Z. Frank (2004), "Is All That Talk Just Noise? The Information Content of Internet Stock Message Boards," Journal of Finance 59(3), 1259-94.

Barberis, Nicholas C. and Richard Thaler (2003), "A Survey of Behavioral Finance," in Handbook of the Economics of Finance, G. Constantinides, R. Stulz, M. Harris eds., North Holland, Amsterdam, 2003.

Barsky, Robert B. and J. Bradford De Long (1993), "Why Does the Stock Market Fluctuate?," Quarterly Journal of Economics, 108: 291311.

Boudoukh, Jacob, Ronen Feldman, Shimon Kogan, and Mathew Richardson (2013), "Which news moves stock prices? A textual analysis," NBER working paper series, No 18725, January.

Boyd, John H, Jian Hu, and Ravi Jagannathan (2005), "The Stock Markets Reaction to Unemployment News: Why Bad News is Usually Good for Stocks," Journal of Finance, 60(2), 649-72.

Campbell, John Y. and Robert J. Shiller (1988a), "The Dividend-Price Ratio and Expectations of Future Dividends and Discount Factors," Review of Financial Studies, 1, 195-227.

(1988b), "Stock Prices, Earnings, and Expected Dividends,"

Journal of Finance, 43, 661-76.

Cornell, Bradford (2013), "What Moves Stock Prices? Another Look," Journal of Portfolio Management, 39(3), 32-8.

Das, Sanjiv and Mike Chen (2007), "Yahoo for Amazon: Opinion Extraction from Small Talk on the Web," Management Science, 53, 137588 . 
Davis, Angela K., Piger, Jeremy M. and Lisa M. Sedor (2006), "Beyond the Numbers: An Analysis of Optimistic and Pessimistic Language in Earnings Press Releases," Working Papers 2006-005, Federal Reserve Bank of St. Louis.

Driffill, John and Martin Sola (1998), "Intrinsic Bubbles and RegimeSwitching," Journal of Monetary Economics, 42, 357-373.

Engelberg, Joseph (2008), "Costly Information Processing: Evidence from Earnings Announcements," AFA 2009 San Francisco Meetings Paper. Available at SSRN: http://ssrn.com/abstract $=1107998$.

Fair, Ray C. (2002), "Events that Shook the Market," Journal of Business, 75(4): 713-731.

Frydman, Roman and Michael D. Goldberg (2015), "Change and Rationality in Macroeconomics and Finance Theory: A New Rational Expectations Hypothesis," New York University and University of New Hampshire Working Paper.

(2011), Beyond Mechanical Markets: Asset Price Swings, Risk and the Role of the State, Princeton, NJ: Princeton University Press.

Gutiérrez, Maria José and Jesús Vázquez (2004), "Switching Equilibria. The Present Value Model for Stock Prices Revisited," Journal of Economic Dynamics and Control, 28, 2297-2325.

Hamilton, J.D. (1988), "Rational-Expectations Econometric Analysis of Changes in Regime: An Investigation of the Term Structure of Interest Rates," Journal of Economics Dynamics and Control, 12, 385-423.

Kaminsky, Graciela (1993), "Is There a Peso Problem?: Evidence from the Dollar/Pound Exchange Rate, 1976-1987," American Economic Review, 83, 450-72.

Keynes, John Maynard (1936), The General Theory of Employment, Interest and Money, Harcourt, Brace and World.

Knight, Frank H. (1921), Risk, Uncertainty and Profit, Boston: Houghton Mifflin. 
Li, Feng (2010), "Textual Analysis of Corporate Disclosures: A Survey of the Literature," Journal of Accounting Literature, 29: 143-65.

Loughran, Tim and Bill MvDonald (2011), "When is a Liability Not a Liability? Textual Analysis, Dictionaries and 10-Ks," Journal of Finance, 66, 35-65.

Mangee, Nicholas (2011), "The Long Swings Puzzle in Equity Markets: Which Way Forward?," Ph.D. Dissertation, University of New Hampshire.

McQueen, Grant and V. Vance Roley (1993), "Stock Prices, News and Business Conditions," The Review of Financial Studies, 6(3): 683-707.

Muth, John F. (1961), "Rational Expectations and the Theory of Price Movements," Econometrica, 29(3), 315-335.

Obstfeld, Maurice (1994), "Models of Currency Crises with Self-Fulfilling Features," European Economic Review, 40, 1037- 1047.

Pearce, Douglas K. and V. Vance Roley (1985), "Stock Prices and Economic News," Journal of Business, 58(1), 49-67.

Sargent, Thomas J. (2005), "An Interview with Thomas J. Sargent," by Evans, George W. and Seppo Honkapohja, Macroeconomic Dynamics, 9, 2005, 561-583.

Shiller, Robert J. (2014), "Speculative Asset Prices," American Economic Review, 104(6), 1486-1517.

(2000), Irrational Exuberance, New York: Broadway Books.

(1981), "Do Stock Prices Move Too much to Be Justified by Subsequent Changes in Dividends?," American Economic Review, 71: 421-36.

Sullivan, Peter (2013), "What Drives Exchange Rates? Do Fundamentals Matter?," Working Paper.

Tetlock, Paul C. (2007), "Giving Content to Investor Sentiment: The Role of Media in the Stock Marke," Journal of Finance, 62(3), 1139-68. 
Tetlock, Paul C., Maytal Saar-Tsechansky and Sofus Macskassy (2008), "More Than Words: Quantifying Language to Measure Firms' Fundamentals," Journal of Finance, 63(3), 1437-67.

Timmermann, Allan (1994), "Present Value Models with Feedback: Solutions, Stability, Bubbles, and Some Empirical Evidence," Journal of Economic Dynamics and Control, 18, 1093-1119.

Vega, Clara and Elizabeth Demers (2008), "Soft Information in News Announcements: News Or Noise?," International Finance Discussion Papers 951, Board of Governors of the Federal Reserve System (U.S.). 